\title{
Effect of anatomic fibula on tibia union and alignment after intramedullary nailing of tibia shaft fractures
}

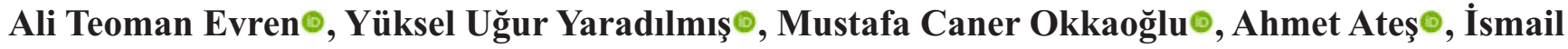 \\ Demirkale $\odot$, Murat Altay $\odot$
}

Department of Orthopaedics and Traumatology, University of Health Sciences, Keçiören Training and Research Hospital, Ankara, Turkey

\begin{abstract}
Objectives: The effect of an intact or fixated fibula on tibial union and alignment in tibial shaft fractures applied with intramedullary nailing is investigated.

Methods: A retrospective examination was made of 67 patients aged 19-85 years who were applied with intramedullary nailing for a tibial shaft fracture (AO-42) between January 2010 and December 2016. The 44 patients included in the study were separated into 2 groups as those with anatomic fibula (Group 1, $\mathrm{n}=12$ ) and those with a fibula fracture which is not fixated (Group 2, n =32). The patients were evaluated in respect of bone union and malalignment from direct radiographs. Union was evaluated according to the RUST criteria, and the threshold for malalignment was taken as $5^{\circ}$ in the coronal and sagittal planes.
\end{abstract}

Results: The patients comprised 24 males and 20 females (M/F: 6/5) with a mean age of 42.7 years (range, 19-76 years). Non-union was observed in 3/12 patients (25\%) in Group 1, and in 2/32 (6.3\%) patients in Group 2 at 6 months. Malalignment was observed in 1/12 (8.3\%) patients in Group 1 (procurvatum) and in 7/32 $(21.8 \%)$ patients in Group 2, of which $3(9.3 \%)$ were varus, and $4(12.5 \%)$ were valgus. The rate of malalignment was significantly lower in Group 1 than in Group 2.

Conclusions: The results demonstrated that bone union of a tibial shaft fracture is slower in patients with an anatomic fibula compared to those with non-anatomic fibula. Although the anatomic fibula slows the rate of union, it prevents malalignment.

Keywords: Tibia shaft fracture, intramedullary nailing, intact fibula, malunion, non-union

$\mathrm{T}$ ibial shaft fractures are the most frequently seen fractures of the long bones [1]. The fast pace of current lifestyles has led to an increasing incidence of motor vehicle accidents and sports accidents [2]. Conservative treatment can be applied in closed fractures with $<10 \mathrm{~mm}$ shortness and $<5^{\circ}$ angulation in any plane [3]. Surgical treatments are generally preferred to reduce complications (joint stiffness, non-union, malalignment) and provide an earlier return to work.
Intramedullary nailing is the gold standard treatment method for tibial shaft fractures. As a minimally invasive and biological method, intramedullary nailing provides symmetrical and dynamic fracture fixation $[4,5]$.

Despite intramedullary nailing applied in tibial shaft fractures, non-union and malalignment may still be seen. In literature, non-union in tibial shaft fractures applied with intramedullary nailing has been reported 
as 5\%-33\%, and malalignment has been reportedas $16 \%$, especially in distal fractures $[6,7]$.

One of the most important factors affecting nonunion and malalignment is the status of the fibula. An intact fibula in tibial shaft fractures, especially in patients aged $>20$ years, has been shown to increase the incidence of delayed union and non-union in the tibia [8]. To the best of our knowledge, there has been no previous study that has directly investigated the effect of the fibula being intact or fixed on tibial union and alignment in tibial fractures applied with intramedullary nailing.

The aim of this study was to investigate the effect of an intact or fixed fibula on tibial bone union and alignment in tibial shaft fractures treated with intramedullary nailing.

\section{METHODS}

A retrospective examination was made of 67 patients aged 19-85 years who were applied with intramedullary nailing for a tibial shaft fracture (AO42) in our clinic between January 2010 and December 2016 (Fig. 1). All the fractures are caused by torsional

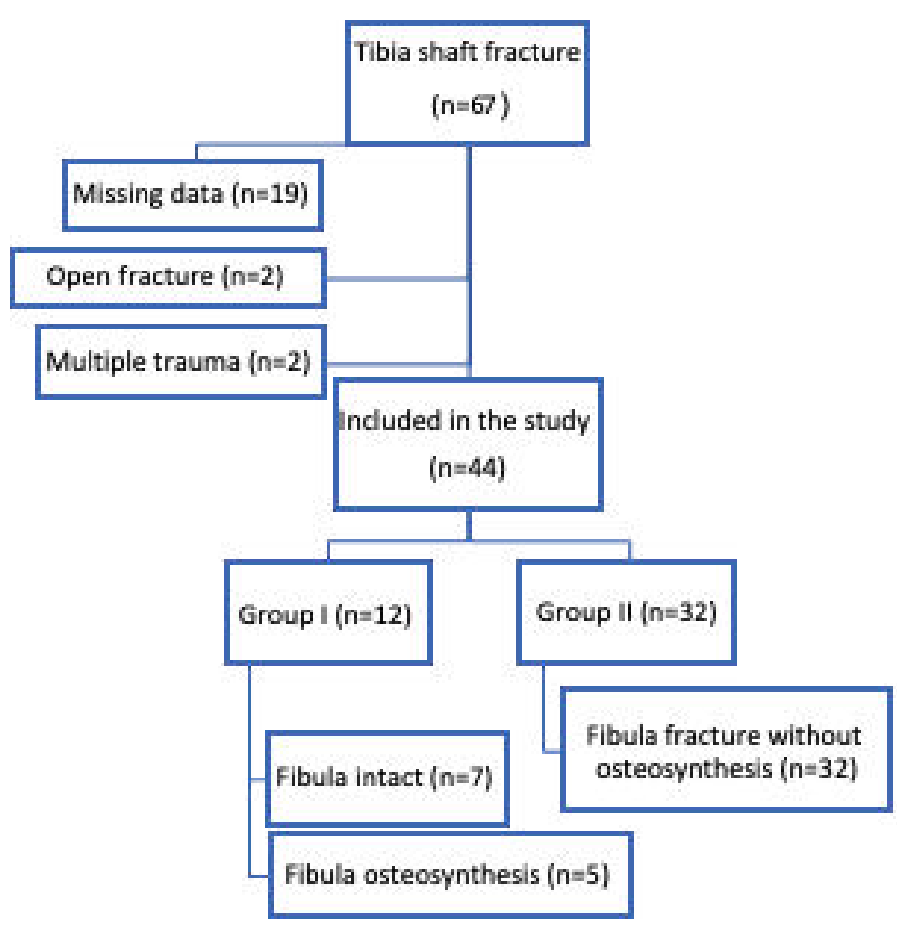

Fig. 1. Follow-up diagram. injury resulted from low energy trauma. In AO classification diaphysis or shaft is located between proximal and distal end segment which is defined as the same length as the widest part of the epiphysis/metaphysis of the bone. Patients were included if they have isolated trauma resulting in tibial shaft fracture with or without fibula fracture. Patients were excluded if they had an open fracture or severe sort tissue injury $(n=2)$, multiple trauma $(n=2)$ or if data were not available $(n=19)$. Group 1 comprised 12 patients with anatomic fibula (intact or fixated if fractured) and tibial shaft fracture, and Group 2 comprised 32 patients with tibial shaft fracture and fibula that is not fixated. These 2 groups were evaluated with the Radiographic Union Scale in Tibial Fractures (RUST) score at 3 weeks, 3 months and 6 months, and in respect of alignment seen on anteroposterior and lateral radiographs taken on postoperative Day 1, at 6 weeks, 3 and 6 months. Patients not showing bone union at 6 months were followed up until union. Bone union can be evaluated with the RUST scoring system. RUST scoring is a radiographic evaluation method with high repeatability and reliability, which is used for tibial shaft fractures applied with intramedullary nailing. A RUST score $\geq 9$ was accepted as union [9]. Malalignment was accepted as angulation $>5^{\circ}$ on anteroposterior and/or lateral radiographs.

\section{Surgical Technique}

Soft tissue was carefully evaluated preoperatively. Each patient was positioned supine on a radiolucent operating table. The $\mathrm{C}$-arm was adjusted to come from the opposite side. Entry was made with an anterior approach to the knee. The tibial plateau was reached by separating the patellar tendon from the centre After closed reduction of the fracture with traction or with a weber clamp percutaneously, a locking, grooved antegrade tibia nail was applied. In patients with a fibula fracture in the distal quarter, which is a part of ankle joint, anatomic fixation of the fibula was applied for ankle stability. Very close follow-up was maintained in the first 24 hours, in respect of compartment syndrome.

\section{Follow-Up}

Postoperatively, patients who did not have a distal quarter fibula fracture were permitted weight-bearing 

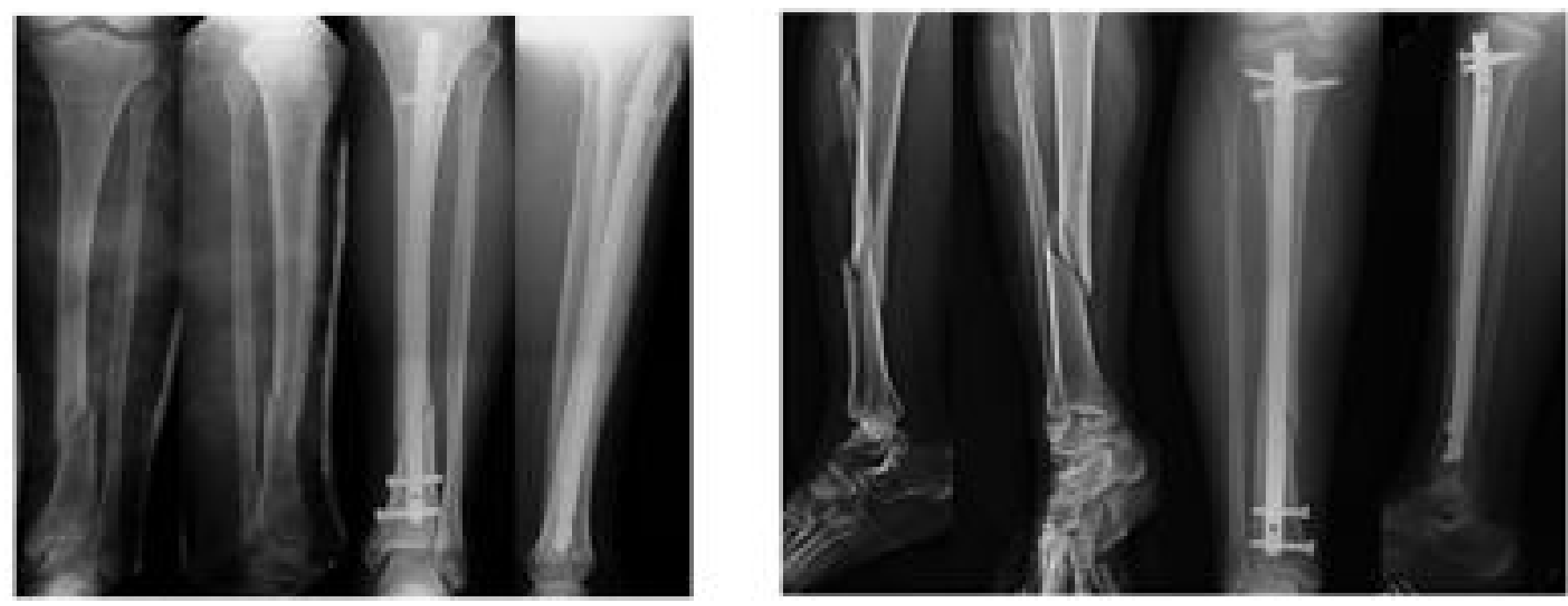

Fig. 2. Cases of intact and fixated fibula (preoperative and postoperative 6th month x-rays).

as tolerated. Patients with a distal fibula fracture were permitted weight-bearing after the 6th week postoperatively. All patients were given DVT prophylaxis and ankle and knee exercises were started in the early postoperative period. Until full bone union was obtained all patients attended regular follow-up examinations. Examples of cases from both groups are shown in Fig. 2.

\section{Statistical Analysis}

Data obtained in the study were analysed statistically using SPSS vn 13 (USA) software. Conformity of parametric values to normal distribution was assessed with the Shapiro Wilk test. Non-parametric variables were evaluated with the Mann Whitney U-test or the Fisher test. A value of $p$ $<0.05$ was accepted as statistically significant.

\section{RESULTS}

The patients comprised 24 males and 20 females (M/F:6/5) with a mean age of 42.7 years (range, 1976 years). The demographic data of the groups are shown in Table 1 . When patients were separated into 2 groups as those aged $<60$ years and $>60$ years, there was no significant difference in respect of the RUST scores at 6 weeks, 3 months and 6 months $(p>0.05)$. No significant difference was determined between the genders in respect of the RUST scores at 6 weeks, 3 months and 6 months $(p>0.05)$.
In Group 1, the mean RUST score was 5.16 at 6 weeks, 7.41 at 3 months, and 9.25 at 6 months. In Group 2, the mean RUST score was 6.59 at 6 weeks, 8.28 at 3 months, and 9.90 at 6 months. The differences at all 3 time points were determined to be statistically significant ( $p=0.040$ ). The time to union was determined as mean 20.8 weeks in Group 1 and mean 15.3 weeks in Group $2(p=0.021)$.

Non-union was observed in 3/12 (25\%)patients in Group 1, and in 2/32 (6.3\%) patients in Group 2 at 6 months. The total rate of non-union was $11 \%$ (Table $2)$. Due to delayed union in the 6th month, dynamisation was applied to 2 patients, and bone marrow injection was administered to 2 patients. In the 12th month, non-union was observed in $1(2.2 \%)$ patient with an isolated tibia fracture. Fibula osteotomy was performed on this patient and union was obtained.

In the 8 patients with malalignment, union was achieved in the 6th month in 3 (37.5\%), and of the 36 patients with normal alignment, non-union was still present in $2(5.6 \%)$ in the 6 th month. The RUST scores at 6 weeks, 3 months and 6 months were observed to be lower in the patients with malalignment compared to those with normal alignment.

Malalignment was observed in $1 / 12(8.3 \%)$ patients in Group 1 (procurvatum) and in 7/32 (21.8\%) patients in Group 2, of which $3(9.3 \%)$ were varus, and $4(12.5 \%)$ were valgus. The rate of malalignment was significantly lower in Group 1 than in Group 2.

The fracture levels were examined in the cases of 
Table 1. Demographic data of patients

\begin{tabular}{lccc}
\hline & $\begin{array}{c}\text { Group 1 } \\
\mathbf{n = 1 2}\end{array}$ & $\begin{array}{c}\text { Group 2 } \\
\mathbf{n = 3 2}\end{array}$ & Total \\
\hline $\begin{array}{l}\text { Age, years, } \\
\text { mean (range) }\end{array}$ & $38.2(19-72)$ & $44.1(23-76)$ & $42.7(19-76)$ \\
Gender & & & \\
Male, $\mathrm{n}(\%)$ & $8(66.6 \%)$ & $16(50 \%)$ & 24 \\
Female, $\mathrm{n}(\%)$ & $4(33.3 \%)$ & $16(50 \%)$ & 20 \\
$\begin{array}{l}\text { BMI, kg/m } \\
\text { mean }(\text { range }\end{array}$ & $27.6(24-35)$ & $26.8(22-34)$ & $27.4(22-35)$ \\
\hline
\end{tabular}

$\mathrm{BMI}=$ Body mass index

Table 2. Comparison of patients follow up data

\begin{tabular}{lccc}
\hline & $\begin{array}{c}\text { Group 1 } \\
\mathbf{n = 1 2}\end{array}$ & $\begin{array}{c}\text { Group 2 } \\
\mathbf{n = 3 2}\end{array}$ & $\begin{array}{c}\text { \% } \\
\boldsymbol{p} \text { value }\end{array}$ \\
\hline Malaligment rate & $1(8.3 \%)$ & $7(21.8 \%)$ & $18 \%$ \\
Nonunion rate of $6^{\text {th }}$ month & $3 / 12(25 \%)$ & $2 / 32(6.2 \%)$ & $11 \%$ \\
\hline RUST score & & & \\
\multicolumn{1}{c}{$6^{\text {th }}$ week } & 5.16 & 6.59 & $\mathbf{0 . 0 4 0}$ \\
\multicolumn{1}{c}{$3^{\text {th }}$ month } & 7.41 & 8.28 & \\
$\quad 6^{\text {th }}$ month & 9.25 & 9.90 & $\mathbf{0 . 0 2 1}$ \\
\hline Union (weeks) & 20.3 & 15.8 & \\
\hline Nonunion in malaligment rate & $1 / 1(100 \%)$ & $2 / 7(30 \%)$ & \\
\hline
\end{tabular}

RUST $=$ RadiographicUnion Scale in Tibial Fractures

malalignment. Of the 37 cases with fibula fracture, 10 were at the same level as the tibia fracture and 27 were at a different level. Fixation was applied to $4(40 \%)$ of the fractures at the same level, and to $4(15 \%)$ of the fractures at different levels.

\section{DISCUSSION}

The application of intramedullary nailing is accepted as the gold standard treatment in the majority of tibial shaft fractures $[10,11]$. No consensus has yet been reached on how a tibial fracture with concomitant fibula fracture or intact fibula should be treated.

The most significant finding of the current study was that when the fibula is intact, union of the tibia fracture is delayed while malalignment is prevented.

Delayed union or non-union of tibial fractures is an important problem because of delayed return to work and treatment becoming complicated. In literature, non-union rates have been reported at 5\%$33 \%$ despite intramedullary nailing [6].

An intact fibula can cause distraction in the fracture line during intramedullary nailing of tibial fractures. It has been reported that $5 \mathrm{~mm}$ distraction of the fracture line in tibial fractures can prolong union to 8-12 months [12]. Isolated tibial fractures have been examined in literature and it has been reported that union problems have been experienced $[13,14]$. In a study by Court Brown et al. [6], 14 isolated tibial fractures were compared with cases of both bone fractures and a significant difference was determined in the time to union (16.7 weeks vs.15.6 weeks). Balaji et al. [15] found the time to union to be mean 19.7 weeks in 56 cases of isolated tibial fracture with intact fibula. In the current study, the mean time to union was 
determined as 20.8 weeks in Group 1 and 15.3 weeks in Group $2(p=0.021)$. The anatomic fibula (intact or with anatomic fixation) was observed to have prolonged the time to union.

Although there is no time limit for non-union in tibial fractures, delayed union is said to be union occurring at 3-4 months and non-union is accepted as no union within 6-8 months [16]. In a study of 1,106 patients applied with intramedullary nailing, Court Brown et al. [17] reported the non-union rate to be $4.4 \%$. In the current study, the non-union rates according to the 6-month RUST scores (RUST $<9$ ) were determined to be $25 \%$ in Group 1 and $6.2 \%$ in Group 2. The difference between the groups was statistically significant $(p=0.040)$. The anatomic fibula was observed to have delayed union of the tibial fracture. At 12 months postoperatively, non-union was observed in $1(2.2 \%)$ patient and revision surgery was performed in this case.

Malalignment is often seen in distal tibial fractures. Zelle et al. [7 ]examined 1,125 patients and observed $16 \%$ malunion in intramedullary nailing applications. De Giacomo et al. [18] reported that modern methods of intramedullary nailing could lead to malunion. In the current study, malalignment was observed in $8(18 \%)$ patients; $1(8.3 \%)$ in Group 1 and $7(21.8 \%)$ in Group 2. The anatomic fibula was found to have reduced malalignment.

In a study by De Giacomo et al. [18] of 122 patients with distal tibial fracture applied with intramedullary nailing, malalignment was observed most in patients with a fibula fracture at the same level as the tibial fracture. Similarly in the current study, malalignment was seen in $4(40 \%)$ of the 10 patients with fractures at the same level and in $4(15 \%)$ of the 27 patients with fractures at different levels.

\section{Limitations}

Limitations of the current study can be said to be the low number of patients and that the groups were not equal in number. In addition, other factors affecting union were not compared (smoking, socioeconomic status, soft tissue status), clinical results and functional scores of the patients are not investigated and rotation of the tibia were not measured. There is a need for further, multi-centre, more extensive studies on this subject.

\section{CONCLUSION}

In conclusion, bone union of tibial fractures seems to be slower in patients with an anatomic fibula compared to those with a non-anatomic fibula. It is thought that the reason for this is that compression of the fracture is prevented by the fibula. Bone union in patients with malalignment is slower than in patients with normal alignment. Malalignment was seen less in patients with anatomic fibula compared to the patients with non-anatomic fibula. Age and gender were not determined to have any effect on bone union.

\section{Conflict of interest}

The authors disclosed no conflict of interest during the preparation or publication of this manuscript.

\section{Financing}

The authors disclosed that they did not receive any grant during conduction or writing of this study.

\section{REFERENCES}

1. Kojima K, Ferreira R. Tibial shaft fracture. Rev Bras Ortop 2011;46:130-5.

2. Court-Brown CM, McBirnie J. The epidemiology of tibial fractures.J Bone Joint Surg Br 1995;77:417-21.

3. Sarmiento A, Latta LL. 450 closed fractures of the distal third of the tibia treated with a functional brace. Clin Orthop Relat Res 2004:428:261-71.

4. Guo JJ, Tang N, Yang HL, Tang TS. A prospective, randomised trial comparing closed intramedullary nailing with percutaneous plating in the treatment of distal metaphyseal fractures of the tibia. J Bone Joint Surg Br 2010;92:984-8.

5. Vallier HA, Cureton BA, Patterson BM. Randomized, prospective comparison of plate versus intramedullary nail fixation for distal tibia shaft fractures. J Orthop Trauma 2011;25:736-41.

6. Court-Brown CM, Christie J, McQueen MM. Closed intramedullary tibial nailing. Its use in closed and type I open fractures. J Bone Joint Surg Br 1990;72:605-11.

7. Zelle BA, Bhandari M, Espiritu M, Koval KJ, Zlowodzki M; Evidence-Based Orthopaedic Trauma Working Group. Treatment of distal tibia fractures without articular involvement: a systematic review of 1125 fractures. J Orthop Trauma 2006;20:76-9.

8. Teitz C, Carter Di Frankel V. Problems associated with tibial fractures with intact fibulae. J Bone Joint Surg 1980;62:770-6.

9. Leow JM, Clement ND, Tawonsawatruk T, Simpson CJ, Simpson AHRW. The radiographic union scale in tibial (RUST) fractures. Bone Joint Res 2016;5:116-21. 
10. Alho A, Ekeland A, Strømsøe K, Follerås G, Thoresen BO. Locked intramedullary nailing for displaced tibial shaft fractures. J Bone Joint Surg Br 1990;72:805-9.

11. Bhandari M, Guyatt GH, Swiontkowski MF, Tornetta P 3rd, Hanson B, Weaver B, et al. Surgeons' preferences for the operative treatment of fractures of the tibial shaft. An international survey. J Bone Joint Surg Am 2001;83-A:1746-52. 12. Russell TA. Fractures of the tibia and fibula. In: Rockwood CA, Green DP, Buckolz RW, Heckman JD, editors. Fractures in adults. 4th ed. Philadelphia: Lippincott; 1996: pp. 2139-57.

13. Jorgensen TE. The influence of the intact fibula on the compression of a tibial fracture or pseudoarthrosis.Acta Orthop Scand 1974;45:119-29.

14. Bone LB, Sucato D, Stegemann PM, Rohrbacher BJ. Displaced isolated fractures of the tibial shaft treated with either a cast or intramedullary nailing. An outcome analysis of matched pairs of patients. J Bone Joint Surg Am 1997;79:1336-41.

15. Balaji SM, Chandra PM, Devadoss S, Devadoss A. The effect of intact fibula on functional outcome of reamed intramedullary interlocking nail in open and closed isolated tibial shaft fractures: a prospective study. Indian J Orthop 2016;50:201-5.

16. Whelan DB, Bhandari M, McKee MD, Guyatt GH, Kreder HJ, Stephen D, et al. Interobserver and intraobserver variation in the assessment of the healing of tibial fractures after intramedullary fixation. J Bone Joint Surg Br 2002;84:15-8.

17. Court-Brown CM. Reamed intramedullary tibial nailing: an overview and analysis of 1106 cases. J Orthop Trauma 2004;18:96-101.

18. De Giacomo A, Tornetta P. Alignment after intramedullary nailing of distal tibia fractures without fibula fixation. J Orthop Trauma 2016;30:561-7. 